\title{
Compatibility Between Monetary and Fiscal Policy Under EMU ${ }^{1}$
}

\author{
Campbell Leith* \\ Simon Wren-Lewis**
}

\author{
*University of Glasgow \\ **University of Exeter
}

\begin{abstract}
The potential importance of fiscal policy in influencing inflation has recently been highlighted, following Woodford (1998), under the heading of the 'Fiscal Theory of the Price Level' (FTPL). Some authors have suggested that this theory provides a rationale for the Pact for Stability and Growth as a necessary condition for the ECB pursuing a policy of price stability. In this paper, we relax the assumptions underpinning the FTPL by developing a two country open economy model, where each country has overlapping generations of non-Ricardian consumers who supply labour to imperfectly competitive firms which can only change their prices infrequently. We examine the case where the two countries have formed a monetary union, but where the fiscal authorities remain independent. We show that the fiscal response required to ensure solvency is greater when consumers are not infinitely lived. In principle, this allows for some compensating behaviour between governments, but we show that the scope for compensation is small The monetary authority can abandon its active targeting of inflation to ensure the solvency of at most one fiscal authority, and any other combination of policies will either result in price level indeterminacy and/or indefinite transfers of wealth between the two economies. Finally, in a series of simulations we show that fiscal shocks have limited impact on output and inflation provided the fiscal authorities meet the (weak) requirements of fiscal solvency. However, when monetary policy is forced to abandon its active targeting of inflation, then fiscal shocks have a much greater impact on both output and inflation.
\end{abstract}

Jel Codes:E10, E63.

Key Words: EMU, Stability and Growth Pact, Monetary Policy, Fiscal Policy, Fiscal Theory of the Price Level

Address for correspondence:

C. B. Leith,

Department of Economics,

University of Glasgow,

Adam Smith Building,

Glasgow G12 8RT

E-Mail: C.B.Leith@socsci.gla.ac.uk

\footnotetext{
${ }^{1}$ We would like to thank Julia Darby, Michael Woodford and participants at seminars at the Universities of Cambridge and Strathclyde for helpful comments on an earlier draft of the paper. We are also grateful to the ESRC (Grant No. L138251050) for financial support. All errors remain our own.
} 


\section{Introduction}

Following Woodford (1995) a literature has developed under the heading of the 'Fiscal Theory of the Price Level'. Under certain conditions ${ }^{2}$ the economy is in one of two regimes - a 'Ricardian' regime where the fiscal authorities act prudently, government debt does not constitute an element of net wealth and monetary policy is free to target inflation, and another, 'non-Ricardian' regime, where fiscal insolvency requires surprise inflation to deflate the nominal value of government debt, irrespective of the stance of monetary policy. In earlier work (Leith and Wren-Lewis (2000)) we relaxed a number of assumptions underlying the Fiscal Theory of the price level, by considering a closed economy with overlapping generations of consumers supplying labour to imperfectly competitive firms which could only adjust their prices infrequently. This economy also had two stable policy regimes: one where the fiscal authorities ensured solvency and monetary policy was 'active' (using the terminology of Leeper (1991)), such that the authorities raised real interest rates when inflation was above target, and another where fiscal insolvency forced the monetary authorities to react 'passively' to inflation by not raising real interest rates. However both monetary and fiscal policy affected inflation in both regimes, and in addition both regimes could occur even if all government debt was indexed.

The Fiscal Theory has also been extended to the open economy in a number of papers $^{3}$. In Woodford (1998) the extension to the case of a monetary union is straightforward in that under the assumptions of the fiscal theory, with the additional simplifying assumption of international risk sharing, the extension to two countries under monetary union simply aggregates the budget constraints of the two countries into a single constraint. Therefore, if one fiscal authority makes no attempt to adjust

\footnotetext{
${ }^{2}$ The Fiscal Theory assumes that the real level of tax revenues and spending are exogenous - the fiscal authorities do not adjust real surpluses to ensure their budget constraint is satisfied in the face of negative fiscal shocks (i.e. fiscal policy is 'active' in the sense of Leeper (1993). It is also assumed that all real seigniorage revenues are repaid to consumers. The description of the economy is completed with the introduction of an infinitely lived yeoman farmer- as a result the ex ante real interest rate is identical to the representative agent's rate of time preference, and is unaffected by monetary policy. Under these conditions, the government's finances are insulated from the effects of monetary policy and, when prices are flexible, the price level adjusts to satisfy the government's budget constraint.

${ }^{3}$ Dupor (2000), Daniel (2001) and Loyo (1998) consider the fiscal theory in the context of two open economies operating under flexible exchange rates, and seek to address the question as to whether or not the FTPL can deliver a determinate nominal exchange rate and price levels in the two economies. Woodford (1998), Bergin (2000) and Sims (1997) consider the case of open economies which have entered into a monetary union with a fixed nominal exchange rate and common monetary policy, but which still operate independent fiscal policies.
} 
future surpluses to ensure solvency then another member state can run sufficient surpluses to compensate for this in terms of the aggregate budget constraint. Essentially, the government of the prudent country buys the debt of the profligate country. When the assumption of international risk sharing is dropped (as in Bergin(2000)), the conclusion that it is only the aggregate budget constraint that determines whether we are in a 'Ricardian' or 'non-Ricardian' regime (Woodford (1998)) still holds, but the prudent government will be transferring the wealth of its citizens abroad and thereby reducing their consumption relative to consumers in the profligate economy. Therefore, it is suggested (see for example, Sims (2000)) that if one member state does not act to stabilise the debt stock, then it is unlikely that other member states will act to compensate this behaviour, and we will find ourselves operating in the world of the Fiscal Theory of the Price Level.

In this paper, section 1, develops a two country open economy model, where unlike the FTPL ${ }^{4}$ - each country has overlapping generations of consumers who supply labour to imperfectly competitive firms which can only change their prices infrequently. Consumers in each country purchase goods produced both at home and abroad. We examine the case where the two countries have formed a monetary union, but where the fiscal authorities remain independent. Canzoneri et al (2001) conjecture that extensions of this kind may be crucial in determining the plausibility of sustainable non-Ricardian regimes in the real world. Our analysis confirms this conjecture. Section 2 analyses the restrictions on monetary and fiscal policy necessary to reach a unique saddlepath-stable rational expectations solution which does not involve indefinite transfers of wealth from the consumers of one economy to the consumers of the other. Section 3 then calibrates the model and compares the macroeconomic consequences of a fiscal shock under the various policy regimes identified in section 3 . Section 4 concludes.

\section{A Two-Country Model under EMU.}

\section{The Consumer's Problem:}

\footnotetext{
${ }^{4}$ Woodford (1996), also considers relaxes the assumption of flexible prices, but retains the assumption of infinitely lived consumers.
} 
A typical home consumer, i, derives utility from consuming a basket of consumption goods, $c_{t}^{i}$, from holding real money balances, $\frac{M_{t}^{i}}{P_{t}}$, and suffers disutility by providing labour services ${ }^{5}, N_{t}^{i}$, We assume that consumers face a constant instantaneous probability of death, $\mathrm{k}$, and can pool the risks associated with the variations in labour supply that arise from staggered price setting. This means that we can write the consumer's certainty equivalent utility function as,

$$
E_{t} U_{t}^{i}=\int_{t}^{\infty}\left[\ln \left(c_{s}^{i}\right)+\chi \ln \left(\frac{M_{s}^{i}}{P_{s}}\right)-\frac{\kappa}{2}\left(N_{s}^{i}\right)^{2}\right] \exp (-(\sigma+k)(s-t) d s
$$

where $\sigma$ is the individual's rate of time preference and the basket of consumption goods is defined by the following CES index applied across home and foreign goods,

$$
c_{s}^{i}=\left[\int_{0}^{1} c_{s}^{i}(z)^{\frac{\theta-1}{\theta}}\right]^{\frac{\theta}{\theta-1}}
$$

Similarly, the consumer price index is given by,

$$
P_{s}=\left[\int_{0}^{1} p(z)^{1-\theta}\right]^{\frac{1}{1-\theta}}
$$

Since there are assumed to be no impediments to trade, the law of one price holds for each individual good, so that the home price index can be re-written as,

$$
P_{s}=\left[\int_{0}^{n} p_{s}(z)^{1-\theta} d z+\int_{n}^{1}\left(\varepsilon_{s} p_{s}^{*}(z)\right)^{1-\theta} d z\right]^{\frac{1}{1-\theta}}
$$

where $\mathrm{p}(\mathrm{z})$ is the home currency price of $\operatorname{good} \mathrm{z}, \mathrm{p}^{*}(\mathrm{z})$ is the foreign currency price of $\operatorname{good} \mathrm{z}$ and $\varepsilon$ is the nominal exchange rate, which we can normalise to a fixed nominal value of 1 under monetary union.

\footnotetext{
${ }^{5}$ This specification is similar in terms of functional form to Obstfeld and Rogoff (1998), although we abandon the assumption of infinitely lived consumers and allow consumers to supply labour to firms rather than act as yeoman-farmers.
} 
The consumer can hold her financial wealth in the form of domestic government bonds, D, foreign bonds, F, and money balances, M. Due to international arbitrage, domestic and foreign bonds earn the same nominal return, R, while domestic consumers receive a share in the profits of domestic firms, $\Pi$. It is assumed that the consumer receives a premium from perfectly competitive insurance companies in return for their financial assets, including money, should they die. This effectively raises the rate of return from holding financial assets by k. Consumer's pay lump sum taxation of $\mathrm{T}_{\mathrm{t}}$. Therefore, the consumer's budget constraint, in real terms, is given by,

$$
d \frac{A_{t}^{i}}{P_{t}}=\left(r_{t}-\lambda\left(\pi_{t}-\pi_{t}^{e}\right)+k\right)\left(\frac{A_{t}^{i}}{P_{t}}-\frac{M_{t}^{i}}{P_{t}}\right)+\left(k-\pi_{t}\right) \frac{M_{t}^{i}}{P_{t}}+\frac{W_{t}}{P_{t}} N_{t}^{i}+\frac{\Pi_{t}}{P_{t}}-\frac{T_{t}}{P_{t}}-c_{t}^{i}
$$

where $\mathrm{A}_{\mathrm{t}}^{\mathrm{i}}$ represents consumer i's financial assets and $r_{t}$ is the ex ante real interest rate.

The parameter $\lambda$ measures the proportion of debt which is nominal. Therefore, when $\lambda=0$ all interest-bearing financial wealth is fully indexed such that the ex post real interest rate enjoyed by holders of the financial asset is equivalent to the ex ante real interest rate. When $\lambda=1$ all interest-bearing financial wealth is nominal and surprise inflation can erode the real value of financial wealth by decreasing the ex post real interest rate relative to the ex ante rate as under the Fiscal Theory. In our policy simulations we shall assume that the economy was initially in steady-state before an unanticipated shock moves the economy away from this steady-state. We shall then track the response of the economy to this shock under different descriptions of monetary and fiscal policy. As a result, when the shock hits the economy it is possible for ex ante real rates to differ from ex post real rates. However, for the remainder of the simulation, due to the pooling of risks resulting from finite lives and stochastic price setting, the economy behaves as if it is operating under perfect foresight. Therefore, we can drop the distinction between ex ante and ex post real rates in other periods other than the initial period, $t$, in which the shock hits. The consumer then has to maximise utility (1) subject to her budget constraint (5) along with the usual solvency conditions. The various first order conditions this implies are as follows.

Firstly, there is the usual consumption Euler equation,

$$
d c_{t}^{i}=(r(t)-\sigma) c_{t}^{i}
$$


Secondly, optimisation yields a money demand equation,

$$
\frac{M_{t}^{i}}{P_{t}}=\chi \frac{c_{t}^{i}}{R_{t}}
$$

Finally, the individual's optimal labour supply decision will satisfy,

$$
N_{t}^{i}=\frac{W_{t}}{P_{t}} \frac{1}{c_{t}^{i} \kappa}
$$

Integrating the consumer's Euler equation forwards and substituting into the intertemporal budget constraint yields the fully solved out version of the consumption function,

$$
c_{t}^{i}=(k+\sigma)\left(\frac{A_{t}^{i}}{P_{t}}+\int_{t}^{\infty}\left(\frac{W_{s}}{P_{s}} N_{s}^{i}+\frac{\Pi_{s}}{P_{s}}-\tau_{s}\right) \exp \left(-\int_{t}^{s}(r(\mu)+k) d \mu\right) d s\right.
$$

If we normalise total population size to one, then by noting that the current size of a generation of size $\mathrm{k}$ when born at time $\mathrm{z}$ is $k \exp (k(z-t))$, we can write aggregate consumption as,

$$
c_{t}=\int_{-\infty}^{t} c_{t}^{i} k \exp (k(i-t)) d i
$$

Applying this aggregation to all variables allows us to derive the aggregate domestic consumption function as,

$$
c_{t}=(k+\sigma)\left(\frac{A_{t}}{P_{t}}+\int_{t}^{\infty}\left(\frac{W_{s}}{P_{s}} N_{s}+\frac{\Pi_{s}}{P_{s}}-\tau_{s}\right) \exp \left(-\int_{t}^{s}(r(\mu)+k) d \mu\right) d s\right.
$$

where the aggregate financial wealth of domestic consumers is made up of their holdings of money, domestic bonds and foreign bonds, $A_{t}=M_{t}+D_{t}+F_{t}{ }^{*}$. 
The relationship between aggregate per capita labour supply and the real wage is given $\mathrm{as}^{6}$,

$$
N_{t}=\frac{W_{t}}{\kappa P_{t}} \int_{-\infty}^{t} \frac{1}{c_{t}^{i}} k \exp (k(i-t)) d i
$$

While the money demand equation is given by,

$$
\frac{M_{t}}{P_{t}}=\chi \frac{c_{t}}{R_{t}}
$$

In the foreign country there will be corresponding equations for labour supply, money demand and consumption.

\section{The Firm's Problem:}

Define the real profits in period $\mathrm{t}$ of the domestic firm, producing good $\mathrm{z}$,

$$
\frac{\pi(z)_{t}}{P_{t}}=\frac{p(z)_{t}}{P_{t}} y(z)_{t}-\frac{W_{t}}{P_{t}} N(z)_{t}
$$

Firms are assumed to maximise the discounted value of these profits. In the absence of capital and without any constraints on price setting the firm would simply maximise profits in each period in a static manner. However, it is assumed that firms are subject to the constraints implied by Calvo (1983) contracts such that at each point in time firms are able to change prices with a probability $\alpha$. As firms cannot adjust their prices continuously, there is an intertemporal dimension to the firm's pricing/output decision. Suppose the firm is able to change price at this point in time, then its objective function for determining that optimal price is given by,

\footnotetext{
${ }^{6}$ In general the non-linear formulation of the labour supply decision means that a simple aggregation in terms of per capita aggregates is not possible. However, upon log-linearisation this equation can be represented in terms of percentage deviations from steady-state of aggregate variables.
} 


$$
V(z)_{t}=\int_{t}^{\infty}\left[\frac{p(z)_{s}}{P_{s}} y(z)_{s}-\frac{W_{s}}{P_{s}} N(z)_{s}\right]\left(\exp \left(-\int_{t}^{s}(r(\mu)+\alpha) d \mu\right) d s\right.
$$

For simplicity it is assumed that the firms production technology is linear, $y(z)_{t}=N(z)_{t}$. The CES form of the utility function implies that the ith consumer's demand for product $\mathrm{z}$ is given by,

$$
c(z)_{t}^{i}=\left(\frac{p(z)_{t}}{P_{t}}\right)^{-\theta} c_{t}^{i}
$$

Integrating demands across consumers and assuming that the home government allocates its spending in the same pattern as home consumers implies that world demand for product $\mathrm{z}$ is given by,

$$
y(z)_{t}=\left(\frac{p(z)_{t}}{P_{t}}\right)^{-\theta}\left(c_{t}+c_{t}^{*}+g_{t}+g_{t}^{*}\right)
$$

where $\mathrm{y}(\mathrm{z}), \mathrm{c}, \mathrm{c}^{*}, \mathrm{~g}$, and $\mathrm{g}^{*}$ are defined as real per capita variables. Given the linear production function, the firm's (per capita) demand for labour will be equivalent to equation (17).

Utilising the home and foreign demands for product $\mathrm{z}$, allows us to rewrite the firm's objective function as,

$$
V(z)_{t}=\int_{t}^{\infty}\left[\left(\frac{p(z)_{s}}{P_{s}}-\frac{W_{s}}{P_{s}}\right)\left(\frac{p(z)_{s}}{P_{s}}\right)^{-\theta} Y_{s}\right]\left(\exp \left(-\int_{t}^{s}(r(\mu)+\alpha) d \mu\right) d s\right.
$$

where the discount rate is raised by the instantaneous probability $\alpha$ to reflect the fact that this price may be in force for some time.

The optimal price implied by the maximisation of this objective function is therefore given by, 


$$
p(z)_{t}=\frac{\int_{t}^{\infty} \theta\left(\frac{1}{P_{s}}\right)^{1-\theta} W_{s}\left(c_{s}+g_{s}+c_{s}^{*}+g_{s}^{*}\right) \exp \left(-\int_{t}^{s}(r(\mu)+\alpha) d \mu\right) d s}{\int_{t}^{\infty}(\theta-1)\left(\frac{1}{P_{t+s}}\right)^{1-\theta}\left(c_{s}+g_{s}+c_{s}^{*}+g_{s}^{*}\right) \exp \left(-\int_{t}^{s}(r(\mu)+\alpha) d \mu\right) d s}
$$

The home output price index, $\mathrm{p}(\mathrm{h})$ is a weighted average of the prices set in the past, where the weights reflect the probability that these prices are still in existence,

$$
p(h)=\left[\int_{-\infty}^{t} \alpha \tilde{p}_{s}^{1-\theta} \exp (-\alpha(t-s)) d s\right]^{\frac{1}{1-\theta}}
$$

where $\tilde{p}_{t}$ is the price set in accordance with equation (19) by those home producers that were able to change prices at that point in time. The aggregate consumer price level is, in turn, given by,

$$
P_{t}=\left[n p(h)_{t}^{1-\theta}+(1-n) p(f)_{t}^{1-\theta}\right]^{\frac{1}{1-\theta}}
$$

and average home output is given by,

$$
y(h)_{t}=\left(\frac{p(h)_{t}}{P_{t}}\right)^{-\theta}\left(c_{t}+g_{t}+c_{t}^{*}+g_{t}^{*}\right)
$$

which, given the linear production technology, means that demand for labour is obtained by summing across the $n$ home firms,

$$
N_{t}=n\left(\frac{p(h)_{t}}{P_{t}}\right)^{-\theta}\left(c_{t}+g_{t}+c_{t}^{*}+g_{t}^{*}\right)
$$

\section{The Government}

The home government's budget constraint in real terms is given by, 


$$
d l_{t}=\left(r_{t}-\lambda\left(\pi_{t}-\pi_{t}^{e}\right)\right)\left(l_{t}-m_{t}\right)-\pi_{t} m_{t}+g_{t}-\tau_{t}
$$

where the total liabilities of the government, 1 comprise government bonds held by home consumers $\left(\mathrm{d}_{\mathrm{t}}\right)$ or by foreign consumers $\left(f_{t}^{*}\right)$, and non-interest bearing money, $\mathrm{m}_{\mathrm{t}}$. The proportion of debt which is nominal is given by $\lambda$. Therefore, a surprise inflation will erode the real value of government debt which is denominated in nominal terms. Aside from borrowing and seigniorage, the government finances spending by levying a lump-sum tax of $\tau_{t}$ on home consumers. Note that while our model allows for surprise inflation eroding the real value of nominal debt as in the FTPL, our budget constraint allows for a number of additional effects not present in the FTPL. Firstly, we do not assume that seigniorage revenues are automatically redistributed to consumers therefore the effects contained in the 'unpleasant monetarist arithmetic' of Sargent and Wallace (1975) are potentially present in our model. Secondly, by introducing nonRicardian consumers and nominal inertia, both monetary policy and fiscal policy can affect real interest rates and thereby, real debt service costs.

The foreign government's budget constraint is given by,

$$
d l_{t}^{*}=\left(r_{t}-\lambda\left(\pi_{t}-\pi_{t}^{e}\right)\right)\left(l_{t}^{*}-m_{t}^{*}\right)-\pi_{t} m_{t}^{*}+g_{t}^{*}-\tau_{t}^{*}
$$

Since the nominal exchange rate is fixed and PPP holds in terms of consumer prices, the real rate of interest payable on government debt, defined in terms of consumer prices, is the same in both countries.

\section{Compatibility Between Monetary and Fiscal Policy.}

\section{The Steady-State}

In this section we assess the stability of our two monetary union economies. In order to do so we first linearise our model around a symmetrical steady-state. We also assume, for simplicity, that the rate of inflation in our steady-state is zero, so that the mis-pricing due to overlapping contracts will not exist in steady-state. Equation (19) 
shows that the optimal price in steady-state, which is the same as that which would be set under flexible prices, is given by

$$
\bar{p}(h)=\frac{\theta}{\theta-1} \bar{W}
$$

Combining this with the labour supply condition, the production function and the national accounting identity (in the symmetrical steady-state the current account will be in balance so that $\bar{y}=\bar{c}+\bar{g}$ ), yields the following equilibrium output,

$$
\bar{y}=\bar{N}=\frac{\bar{g} \pm \sqrt{\bar{g}^{2}+\frac{4(\theta-1)}{\theta \kappa}}}{2}
$$

If government spending is set equal to zero, then this is identical to the steady-state output found in Obsfeldt and Rogoff. ${ }^{7}$

The steady-state consumption function becomes,

$$
\bar{c}=(k+\sigma)\left(\frac{(\bar{y}-\bar{\tau})}{\bar{r}+k}+\frac{\bar{D}+\bar{F}}{\bar{P}}+\frac{\bar{M}}{\bar{P}}\right)
$$

the domestic government's budget constraint becomes,

$$
\frac{\bar{D}+\bar{F}^{*}}{\bar{P}}=\frac{\bar{\tau}-\bar{g}}{\bar{r}}
$$

and money demand is given by,

$$
\bar{m}=\chi \frac{\bar{c}}{\bar{r}}
$$

Note that in this symmetrical equilibrium, with PPP due to free trade, it will also be the case that the real value of debt held overseas will be the same in both countries,

\footnotetext{
${ }^{7}$ A benevolent social planner would maximise individual utility by choosing $\mathrm{C}$ (taking $\mathrm{G}$ as given) in the following objective function, $\ln (c)-\frac{\kappa}{2}(c+g)^{2}$ which would yield a higher steady-state output level which removes the distortion due to imperfect competition, $\bar{y}=\bar{N}=\frac{\bar{g} \pm \sqrt{\bar{g}^{2}+\frac{4}{\kappa}}}{2}$
} 
$\frac{\bar{F}^{*}}{\bar{P}}=\frac{\bar{F}}{\bar{P}}$. This fact, combined with equations (27)-(30), will determine the steadystate value of real assets in the model, along with the equilibrium real interest rate, which is given by,

$$
\bar{r}=\frac{1}{2} \frac{(\bar{y}-\bar{g}) \sigma+\sqrt{(\bar{y}-\bar{g})\left(\sigma^{2}(\bar{y}-\bar{g})+4 k(k+\sigma)(\bar{\tau}-\bar{g})\right.}}{\bar{y}-\bar{g}}
$$

Since consumers are not infinitely lived, the real interest rate is not identical to consumers' rate of time preference, but will be affected by the outstanding stock of government liabilities, since these liabilities constitute consumers' net wealth.

Appendix 1 details the bg-linearisation of the model around this steady-state, such that our two-country model can be described by the following equations. Firstly, the staggered price setting behaviour of our imperfectly competitive firms generates an open economy version of the New Keynesian Phillips curve,

$$
d \hat{\pi}(h)_{t}=\bar{r} \hat{\pi}(h)_{t}-\alpha(\alpha+\bar{r})\left(\hat{c}_{t}+\hat{y}_{t}\right)-\frac{\alpha(\alpha+\bar{r})}{\theta}\left(\frac{1}{2} \hat{y}_{t}-\frac{1}{2} \hat{y}_{t}^{*}\right)
$$

In standard closed-economy formulations of the New Keynesian Phillips curve, current excess inflation is related to expected future output gaps as firms, which can only renegotiate price contracts at random intervals, raise prices now in anticipation of workers demanding higher wages to supply the labour required to produce higher output in the future. Our model reflects the same basic mechanism, but recognises that workers desire to consume more includes not only consumer goods, but also leisure. Therefore, the wage increases required to secure more labour to increase production are greater when that production goes to satisfy an increase in domestic consumption, rather than increased government purchases or foreign consumption. These effects explain the differential impacts of domestic consumption, domestic output and foreign output on output price inflation. The corresponding equation for the foreign economy is given by,

$$
d \hat{\pi}(f)_{t}=\bar{r} \hat{\pi}(f)_{t}-\alpha(\alpha+\bar{r})\left(\hat{c}_{t}^{*}+\hat{y}_{t}^{*}\right)-\frac{\alpha(\alpha+\bar{r})}{\theta}\left(\frac{1}{2} \hat{y}_{t}^{*}-\frac{1}{2} \hat{y}_{t}\right)
$$


The demand curve derived from the CES utility function implies the following definition of average home firm output,

$$
\hat{y}_{t}=-\theta \hat{p}(h)_{t}+\theta \hat{P}_{t}+\frac{1}{2}\left(\frac{1-\bar{g}}{\bar{y}}\left(\hat{c}_{t}+\hat{c}_{t}^{*}\right)+\frac{\bar{g}}{\bar{y}}\left(\hat{g}_{t}+\hat{g}_{t}^{*}\right)\right)
$$

and average foreign firm output,

$$
\hat{y}_{t}^{*}=-\theta \hat{p}(f)_{t}+\theta \hat{P}_{t}^{*}+\frac{1}{2}\left(\frac{1-\bar{g}}{\bar{y}}\left(\hat{c}_{t}+\hat{c}_{t}^{*}\right)+\frac{\bar{g}}{\bar{y}}\left(\hat{g}_{t}+\hat{g}_{t}^{*}\right)\right)
$$

The path for consumption in each economy follows the Euler equation, which for the home country is,

$$
d \hat{c}_{t}=(\bar{r}+k-(k+\sigma)(1+\chi)) \hat{c}_{t}+\bar{r} \hat{r}_{t}-k(k+\sigma) \frac{\bar{\tau}-\bar{g}+\chi \bar{c}}{\overline{r c}} \hat{a}_{t}
$$

and for the foreign country,

$$
d \hat{c}_{t}^{*}=(\bar{r}+k-(k+\sigma)(1+\chi)) \hat{c}_{t}^{*}+\overline{r r}_{t}-k(k+\sigma) \frac{\bar{\tau}-\bar{g}+\chi \bar{c}}{\overline{r c}} \hat{a}_{t}^{*}
$$

These are the usual consumption Euler equations, adjusted for holdings of money balances and allowing for the possibility that finites lives mean that government debt constitutes an element in net wealth. Note that whenk=0, consumers live forever and the level of government debt has no impact on consumption.

Given these optimal paths for consumption, the private sector's assets will evolve according to,

$$
d \hat{a}_{t}=\overrightarrow{r a} \hat{t}_{t}+\overline{r r}_{t}-(1+\chi) \frac{\overline{r c}}{\bar{\tau}-\bar{g}+\chi \bar{c}} \hat{c}_{t}+\frac{\overline{r y}}{\bar{\tau}-\bar{g}+\chi \bar{c}} \hat{y}_{t}-\frac{\bar{\tau} \bar{r}}{\bar{\tau}-\bar{g}+\chi \bar{c}} \hat{\tau}_{t}
$$

Again there is a corresponding equation for the foreign economy, 


$$
d \hat{a}_{t}=\bar{r} \hat{a}_{t}^{*}+\overline{r r}_{t}-(1+\chi) \frac{\overline{r c}}{\bar{\tau}-\bar{g}+\chi \bar{c}} \hat{c}_{t}^{*}+\frac{\overline{r y}}{\bar{\tau}-\bar{g}+\chi \bar{c}} \hat{y}_{t}^{*}-\frac{\bar{\tau} \bar{r}}{\bar{\tau}-\bar{g}+\chi \bar{c}} \hat{\epsilon}_{t}^{*}
$$

In this open economy model, private wealth in one country is not synonymous with the level of public sector liabilities in that country. Any increase in the level of the financial wealth of the private sector relative to the liabilities of the government implies an increase in holdings of foreign debt. In fact, the flow budget constraints of our government are given by,

$$
d \hat{l}_{t}=\overline{r_{t}}+\bar{r} \hat{r}_{t}-\frac{\chi \overline{c r}}{\bar{\tau}-\bar{g}+\chi \bar{c}}\left(\frac{1}{2} \hat{c}_{t}+\frac{1}{2} \hat{c}_{t}^{*}\right)-\frac{\bar{\tau} \bar{r}}{\bar{\tau}-\bar{g}+\chi \bar{c}} \hat{\tau}_{t}
$$

and for the foreign government,

$$
d \hat{l}_{t}^{*}=\bar{r} \hat{l}_{t}^{*}+\bar{r} \hat{r}_{t}-\frac{\chi \overline{c r}}{\bar{\tau}-\bar{g}+\chi \bar{c}}\left(\frac{1}{2} \hat{c}_{t}+\frac{1}{2} \hat{c}_{t}^{*}\right)-\frac{\bar{\tau} \bar{r}}{\bar{\tau}-\bar{g}+\chi \bar{c}} \hat{\tau}_{t}^{*}
$$

There are also two global market clearing conditions. Firstly, for the goods market,

$$
\hat{y}_{t}+\hat{y}_{t}^{*}=\frac{1-\bar{g}}{\bar{y}}\left(\hat{c}_{t}+\hat{c}_{t}^{*}\right)+\frac{\bar{g}}{\bar{y}}\left(\hat{g}_{t}+\hat{g}_{t}^{*}\right)
$$

and, secondly, for the asset market,

$$
\hat{a}_{t}+\hat{a}_{t}^{*}=\hat{l}_{t}+\hat{l}_{t}^{*}
$$

All that remains is to complete our description of monetary and fiscal policy.

\section{Describing Policy:}

In describing policy we assume that the monetary and fiscal authorities implement simple rules. This allows us to obtain tractable results despite the underlying complexity of the model. It also allows us to make clear comparisons with other studies in the literature which have utilised these simple rules (see, for example, 
Leeper (1991), Woodford (1998) and Sims (1997)). We assume that the common monetary policy involves setting real interest rates to target inflation so that, $r_{t}=\bar{r}+m \pi_{t}$, which implies

$$
\hat{r}_{t}=\frac{m}{\bar{r}} \hat{\pi}_{t}
$$

Due to the equality of real rates across the economies and the existence of PPP in consumer prices, this is consistent with a monetary policy which sets European interest rates to target Europe-wide consumer (or output) price inflation.

Now suppose fiscal policy acts to stabilise the liabilities of each fiscal authority independently. We follow Sims (1997) in formulating a simple rule as follows,

$$
\tau_{t}=\phi_{o}+\phi_{1} l_{t}
$$

This rule can be log-linearised as,

$$
\hat{\tau}_{t}=\phi_{1} \frac{\bar{\tau}-\bar{g}}{\bar{r} \tau} \hat{l}_{t}
$$

in the home economy and,

$$
\hat{\tau}_{t}^{*}=\phi_{1}^{*} \frac{\bar{\tau}-\bar{g}}{\bar{r} \bar{\tau}} \hat{l}_{t}^{*}
$$

in the foreign economy.

\section{Necessary Conditions for Saddle-Path Stability:}

We now analyse the necessary conditions for saddle-path stability in our model, in an attempt to discover any tensions/interactions in the setting of monetary and fiscal policy within our two-country model. Before doing so it is helpful to discuss why analysing policy configurations which are consistent with saddlepath stability is useful. Some papers which attempt to apply the FTPL to EMU simply ask whether or not the price level is determined by monetary or fiscal policy (see Woodford (1998) for 
example) by examining whether or not the aggregate budget constraint across the monetary union places us in a Ricardian or non-Ricardian regime. Other authors (see for example Bergin (2000) or Sims (1997)) note that by only looking at the aggregate budget constraint we may observe policy configurations where there are indefinite transfers of wealth from the citizens of one economy to the other. We would like to rule out such policies as being unsustainable, for the reasons set out in Canzoneri et al (2001).

In our model, it is not possible to a priori divide policy into 'Ricardian' or 'non-Ricardian' regimes since at all points in time monetary and fiscal policy jointly determine the values of real and nominal magnitudes in our economies. However we can examine the conditions under which various monetary and fiscal policy combinations can deliver saddlepath stability. In other words we can identify the conditions under which policy will generate a unique path for prices under rational expectations and ensure that both countries' stocks of financial assets and liabilities return to their steady-state values following a temporary shock.

To undertake this stability analysis it is helpful to represent our economies as a dynamic system in matrix algebra form. This can be achieved quite easily as follows. First of all, note that the global market clearing conditions, allow us to eliminate one of our financial asset/liability variables from the system since it is determined as a residual of the other three. We choose to drop $\hat{a}_{t}^{*}$, although the choice is immaterial ${ }^{8}$. Similarly we can eliminate $\hat{y}_{t}^{*}$ from all equations using the condition for market clearing in the goods market. Finally, noting that the definition of consumer prices implies that $\hat{P}_{t}=\frac{1}{2} \hat{p}(h)_{t}+\frac{1}{2}\left(\hat{p}(f)_{t}\right)$ it can be seen that home firm output (34) depends upon aggregate demand and the real exchange rate, which can be defined as, $\hat{e}_{t}=\hat{p}(h)_{t}-\hat{p}(f)_{t}$. Therefore, any terms in domestic output can be replaced with a combination of the real exchange rate and the components of aggregate demand, $\hat{c}_{t}, \hat{c}_{t}^{*}, \hat{g}_{t}$ and $\hat{g}_{t}^{*}$, although we also need to add an equation describing the evolution of the real exchange rate,

\footnotetext{
${ }^{8}$ In fact it is possible to represent the dynamic system in a number of ways. For example, by differentiating the equations for output, we can replace the dynamic equation for the real exchange rate with a dynamic equation for domestic output - however the underlying dynamic systems are identical and as a result so are the stability conditions we derive below.
} 


$$
d \hat{e}_{t}=\hat{\pi}(h)_{t}-\hat{\pi}(f)_{t}
$$

By adding the description of policy outlined above, we can represent the two economies in matrix form as follows, 


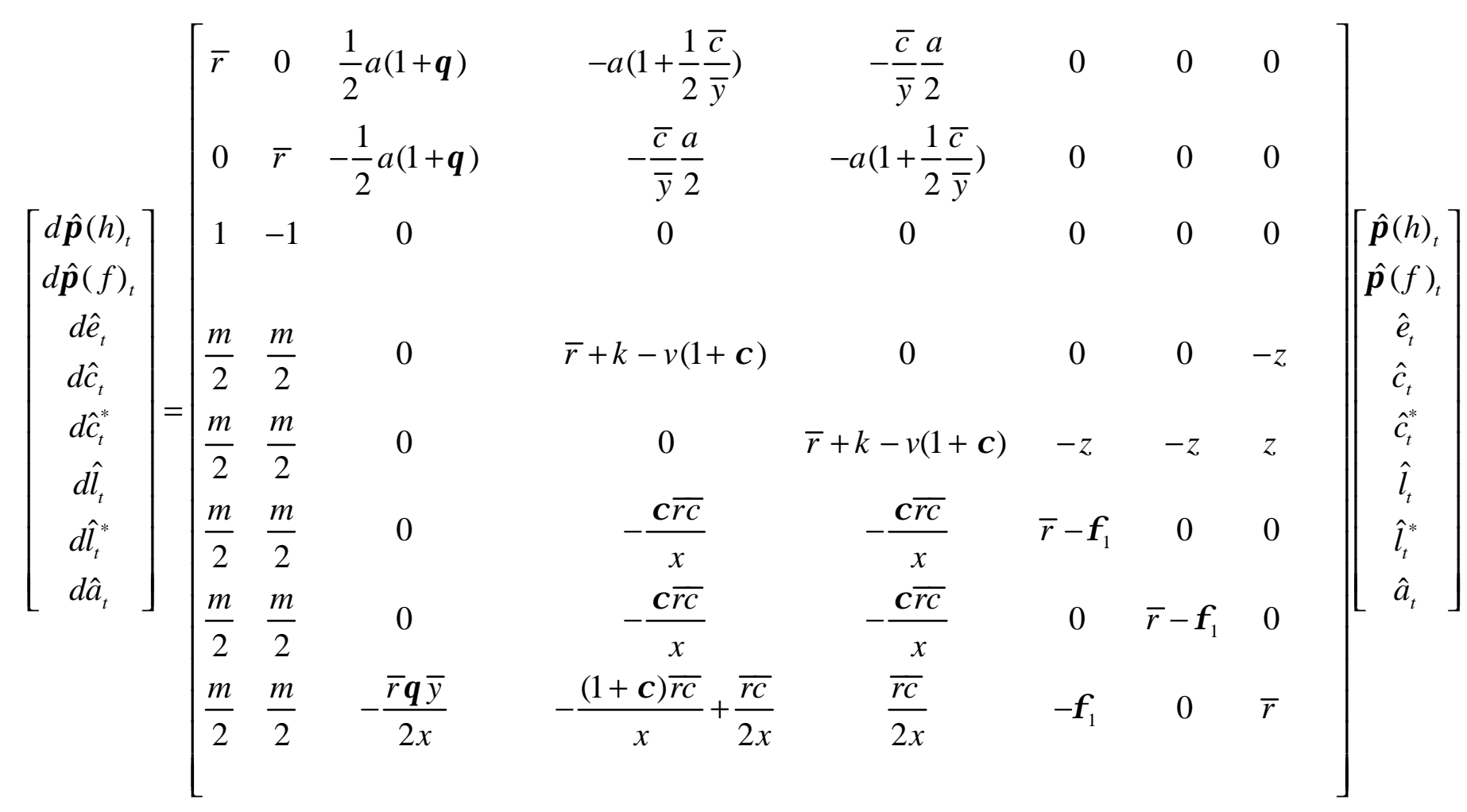

where $a=\alpha(\alpha+\bar{r}), v=k+\sigma$ and $z=k(k+\sigma) \frac{\bar{\tau}-\bar{g}+\chi \bar{c}}{\overline{r c}}$ and $x=\bar{\tau}-\bar{g}+\chi \bar{c}$. 
The constraints on policy required to ensure a dynamically stable economy are probably clearer, if we assume that the economy approaches its cashless $\operatorname{limit}^{9}$ (as in Woodford (1998)) i.e. $\chi \rightarrow 0$. This has the implication that the central bank retains control over nominal interest rates, but that the contribution of seigniorage revenues to government finances are negligible. Woodford (op. cit.) shows that this cashless economy retains the essential features of the FTPL and this is confirmed for a closed economy with sticky prices and non-Ricardian consumers in Leith and Wren-Lewis (2000).

The determinant of the transition matrix of our two country model is given by,

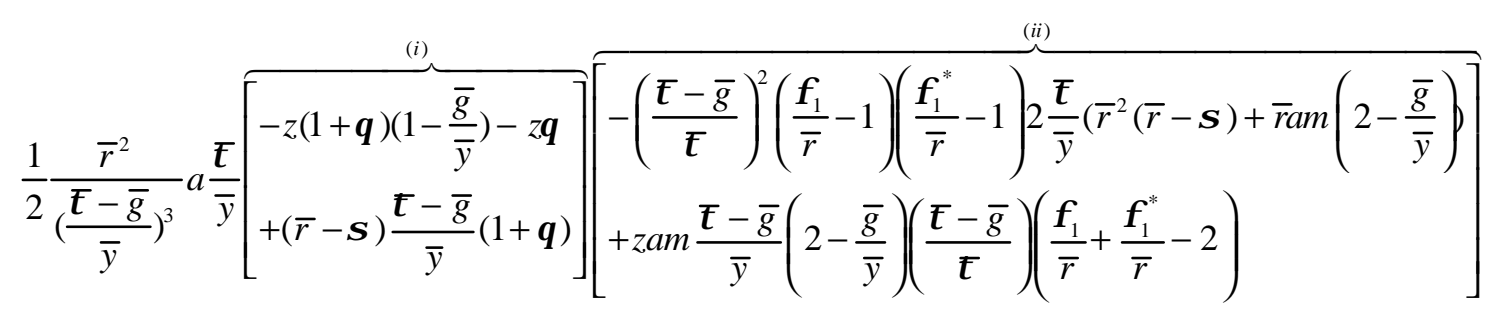

A necessary condition for stability is that the determinant of this matrix be positive, since we require four eigenvalues with negative real parts (corresponding to the predetermined variables ${ }^{10}, \hat{e}_{t}, \hat{a}_{t}, \hat{l}_{t}$ and $\hat{l}_{t}^{*}$ ) and four eigenvalues with positive real parts relating to the 'jump' variables in the system $\left(\hat{\pi}(h)_{t}, \hat{\pi}(f)_{t}, \hat{c}_{t}^{*}\right.$, and $\left.\hat{c}_{t}\right)$.

The first thing to note is that the expression within the square brackets labelled (i), is unambiguously positive and does not contain any of the parameters within the policy rules ${ }^{11}$. Therefore in assessing the determinant condition for stability we need only consider the expression within the second square brackets, labelled (ii), which must be positive as a necessary condition for saddlepath stability. In this context

\footnotetext{
${ }^{9}$ Even if we allowed for seigniorage revenues, for plausible values of $\chi$ the stability conditions shown here are not materially affected. These more complex conditions are available from the authors upon request. The numerical analysis that follows this section allows for non-zero values of $\chi$.

${ }^{10}$ It should be noted that the initial values of real government liabilities and private sector assets, may be influenced by any surprise inflation if they are denominated in nominal terms. However, since they are not themselves free to jump to any level to eliminate the influence of unstable eigenvalues on the dynamic system they should not be considered to be 'jump' variables.

${ }^{11}$ To do so substitute the expression for the equilibrium real interest rate, equation (31) into (i) and

rearrange to give,

$$
-z(1+\theta)\left(1-\frac{\bar{g}}{\bar{y}}\right)+(\bar{r}-\sigma) \frac{\bar{\tau}-\bar{g}}{\bar{y}}(1+\theta)-z \theta
$$$$
=2 \frac{(k+\sigma) k(\bar{\tau}-\bar{g})[(2 \theta+1) \bar{y}-\bar{\tau}(1+\theta)]}{\bar{y}^{2}\left[(\bar{y}-\bar{g}) \sigma+\sqrt{(\bar{y}-\bar{g})\left(\sigma^{2}(\bar{y}-\bar{g})+4 k(k+\sigma)(\bar{\tau}-\bar{g})\right.}\right]}>0
$$ 
saddlepath stability implies that all variables in the system will return to the steadystate following a temporary fiscal shock - this implies that we are not considering the possibility of one government indefinitely accumulating the debt of the other government. If we were to allow this then we could simply aggregate the equations across the two economies and reduce the system to a closed economy model of the type analysed in Leith and Wren-Lewis (2000).

\section{Compatibility Between Monetary and Fiscal Policy}

One way to look at stability is to consider how the monetary authorities may be constrained by various combinations of member states' fiscal policies. To see this we can derive a necessary stability condition in terms of the monetary policy feedback parameter, $\mathrm{m}$. It is possible to show that the determinant will be positive whenever,

$$
\begin{aligned}
& m>\Psi \text { when (iii) }>0, \text { and } \\
& m<\Psi \text { when (iii) }<0 .
\end{aligned}
$$

Where $\Psi=-\frac{2\left(\phi_{1}-\bar{r}\right)\left(\phi_{1}{ }^{*}-\bar{r}\right)(\bar{r}-\sigma) \bar{r}}{\alpha(\alpha+\bar{r})\left(2-\frac{\bar{g}}{\bar{y}}\right) \underbrace{\left[2\left(\phi_{1}-\bar{r}\right)\left(\phi_{1}{ }^{*}-\bar{r}\right)-z\left(\phi_{1}+\phi_{1}{ }^{*}-2 \bar{r}\right)\right]}_{(i i i)}}$

The case where $m>\Psi$ can be thought of as analagous to Leeper's (1991) 'active' monetary policy regime, in the sense that here the monetary authorities are free to raise real interest rates in response to excess inflation to whatever degree they wish beyond $\Psi$. While, the case of $m<\Psi$ implies that the monetary authorities are constrained in their ability to raise interest rates in response to excess inflation. When consumers are Ricardian, then $\bar{r}=\sigma$ and $\Psi=0$ so that this case is identical to that of Leeper (1991).

We can therefore identify the restrictions on fiscal policy that are necessary (although possibly not sufficient) for the monetary authorities to follow an active monetary policy such that, $m>\Psi$. These are, 


$$
\begin{aligned}
& \phi_{1}^{i}>\bar{r}+\frac{k(k+\sigma)\left(\phi_{1}^{j}-\bar{r}\right)}{2\left(\phi_{1}^{j}-\bar{r}\right)-k(k+\sigma) \frac{(\bar{\tau}-\bar{g})}{\overline{r y}}} \\
& \phi_{1}^{j}>\bar{r}+\frac{1}{2} k(k+\sigma) \frac{(\bar{\tau}-\bar{g})}{2 \bar{r} \bar{\tau}}
\end{aligned}
$$

where, the $\mathrm{i}$ and $\mathrm{j}$ reflect the two different fiscal authorities such that $i \neq j$.

In the necessary conditions described by equation (49) both fiscal authorities are acting to stabilise their debt stocks in the face of any shocks hitting the government's finances. What these conditions imply can be seen by considering Figure 1.

$\underline{\text { Figure } 1 \text { - Compatibility Between Monetary and Fiscal Policy }}$

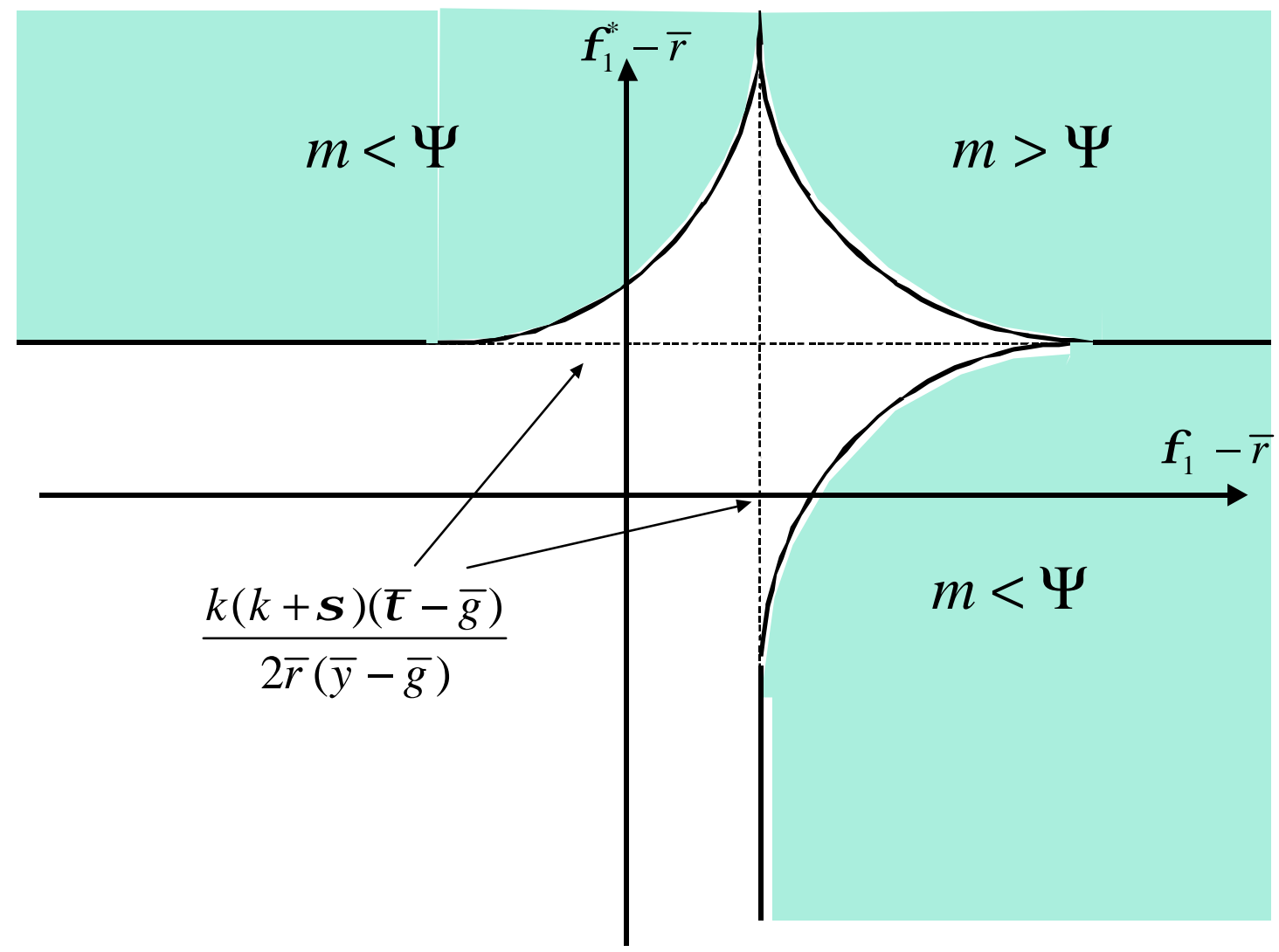

In Figure 1 the $\mathrm{x}$-axis measures the value of $\phi_{1}-\bar{r}$, while the $\mathrm{y}$-axis measures, $\phi_{1}^{*}-\bar{r}$. The shaded area in the North-East quadrant, labelled $m>\Psi$, represents the combinations of fiscal feedback parameters that satisfy the inequalities in (49) and which support saddle-path stability in our two economies. 
There are several features of these stability conditions that are worth emphasising. The presence of non-Ricardian consumers raises the threshold level of fiscal feedback necessary to ensure fiscal solvency when monetary policy is active. In the case of Ricardian consumers the requirements for fiscal solvency would simply be $\phi_{1}>\bar{r}$ and $\phi_{1}^{*}>\bar{r}$ (as in Sims (1997)). This would ensure that both fiscal authorities were solvent and that there was no indefinite transfer of wealth from one country to another. ${ }^{12}$ The intuition behind why the presence of non-Ricardian consumers requires larger fiscal feedback is straightforward. Consider a positive shock to debt. With nonRicardian consumers, this will add to net wealth and raise consumption. This will, in turn, raise demand and inflation, which with an 'active' monetary policy will raise real interest rates, aggravating the potential debt-interest spiral. As a result, fiscal feedback has to be greater than the steady-state real rate since the actual real rate is above steady-state.

In our model, the conditions for individual fiscal solvency are not only raised above this threshold, but they depend upon the fiscal response of other monetary union members. The solid rectangular hyperbola traces the combinations of fiscal feedback that are necessary to ensure that a saddlepath-stable rational expectations equilibrium exists with sustainable levels of debt in both economies. Therefore, even when we impose the condition that debt in each country should be stable, as well as in aggregate, there is scope for compensation between fiscal authorities. However, the degree of trade-off is non-linear - any country not doing enough to stabilise its debt stock will require a far greater response from the other country to ensure individual solvency. Additionally, there are limits to the degree to which one country can compensate another. If one authority has a fiscal response which is less than $\bar{r}+\frac{k(k+\sigma)(\bar{\tau}-\bar{g})}{2 \bar{r}(\bar{y}-\bar{g})}$, and the monetary authority is 'actively' targeting inflation, then it will not be possible for another fiscal authority to compensate no matter how great their fiscal response, without accumulating the debt of the 'lax' fiscal authority. Finally, it should be noted that although these are necessary, but not necessarily sufficient conditions, numerical evaluation of the eigenvalues of the transition matric

\footnotetext{
${ }^{12}$ If we were simply interested in the issue of price level determinacy alone then the usual FTPL condition would be $\frac{1}{2} \phi_{1}+\frac{1}{2} \phi_{1}{ }^{*}>\bar{r}$ and there would be a straight trade-off between the fiscal responses of the two authorities.
} 
for plausible parameter values suggests that these necessary conditions are also sufficient.

Another set of necessary conditions for saddlepath stability when monetary policy is active can be derived as,

$$
\begin{aligned}
& \phi_{1}^{i}<\bar{r}+\frac{k(k+\sigma)\left(\phi_{1}^{j}-\bar{r}\right)}{2\left(\phi_{1}^{j}-\bar{r}\right)-k(k+\sigma) \frac{(\bar{\tau}-\bar{g})}{\overline{r y}}} \\
& \phi_{1}^{j}<\bar{r}+\frac{1}{2} k(k+\sigma) \frac{(\bar{\tau}-\bar{g})}{2 \bar{r} \bar{\tau}}
\end{aligned}
$$

Here neither fiscal authority is attempting to stabilise its debt stock. However, in this case numerical evaluation of the eigenvalues of the transition matrix suggests that even if this condition is satisfied the economy is never saddlepath stable. The intuition is quite straightforward - a single monetary policy cannot ensure fiscal solvency under two independent fiscal authorities when those two authorities both fail to act to stabilise their debt stocks. This result also applies in the case of Ricardian consumers and flexible prices since a single price level cannot adjust to ensure that the budget constraints of two independent fiscal authorities are satisfied (see Canzoneri et al (2001)). We can, therefore, ignore this combination of policy parameters in examining stable policy spaces.

We can also examine the case where the monetary authority has opted not to follow an active monetary policy. Here the stability conditions are given by,

$$
\begin{aligned}
& \phi_{1}^{i}<\bar{r}+\frac{k(k+\sigma)\left(\phi_{1}^{j}-\bar{r}\right)}{2\left(\phi_{1}^{j}-\bar{r}\right)-k(k+\sigma) \frac{(\bar{\tau}-\bar{g})}{\overline{r y}}} \\
& \phi_{1}^{j}>\bar{r}+\frac{1}{2} k(k+\sigma) \frac{(\bar{\tau}-\bar{g})}{2 \bar{r} \bar{\tau}}
\end{aligned}
$$

Here one fiscal authority is acting to stabilise its debt stock, while the other is not doing so. These combinations are given by the shaded areas in the North-West and South-East quadrants, labelled $m<\Psi$. In these cases the monetary authorities have been forced to abandon their active monetary policy to support an insolvent fiscal authority. The other fiscal authority then has to act to ensure fiscal solvency on its 
own - as noted above the monetary authority cannot act to stabilise the debt of two insolvent authorities. It is also interesting to note that when one fiscal authority is only mildly insolvent then the solvent fiscal authority has to have a very large degree of fiscal feedback to ensure saddlepath stability.

This analysis suggests that we can identify two underlying policy regimes. Firstly, for monetary policy to be able to adjust nominal interest rates such that real rates are free to rise in response to excess inflation then it is necessary for both fiscal authorities to be adjusting their fiscal instruments to ensure fiscal solvency. Within this regime there can be some degree of compensation between fiscal authorities, in that a moderate fiscal response on the part of one fiscal authority will not compromise the ECB's attempts to target inflation if another fiscal authority is sufficiently aggressive in stabilising its stock of government liabilities.

The second regime we can identify, is where one fiscal authority does not meet the critical degree of fiscal feedback needed to ensure fiscal solvency when the ECB gears monetary policy towards the control of inflation. In this case the ECB must abandon its attempt to 'actively' control inflation and adopt a monetary policy which will not destabilise the debt stock of the recalcitrant fiscal authority. The remaining fiscal authorities must act to stabilise their own liabilities - it would only be possible for the ECB to assist more than one fiscal authority if their economies and the shocks hitting them were perfectly symmetrical. Any other combination of policy is unsustainable in that there would be indefinite transfers of wealth between union members.

\section{Calibration and Simulation of the Model:}

In order to discuss the policy implications for different degrees of fiscal rectitude under a common monetary policy, we need to adopt parameter values for our model. We assume that a unit of time corresponds to a quarterly data period. Accordingly, the parameters we choose are given in Table 1, along with the steadystate values these imply. 
Table 1 - Parameters and Steady-State

\begin{tabular}{|l|l|l|l|l|}
\hline Parameter & Value & Variable & $\begin{array}{l}\text { Steady- } \\
\text { State } \\
\text { Value }\end{array}$ & $\begin{array}{l}\text { Steady-State Value } \\
\text { as percentage of } \\
\text { annual GDP }\end{array}$ \\
\hline$\theta$ & 8 & $\bar{y}$ & 1 & $100 \%$ \\
\hline$\sigma$ & $\ln (1.007)$ & $\bar{r}$ (annualised) & 0.03 & N.A. \\
\hline $\mathrm{k}$ & 0.0083 & $\bar{h}$ & 46.84 & $1171 \%$ \\
\hline$\tau$ & 0.25 & $\bar{a}=\bar{l}$ & 2.8 & $70 \%$ \\
\hline$\alpha$ & 0.287 & $\bar{c}$ & 0.77 & $77 \%$ \\
\hline$\kappa$ & 0.9257 & $\bar{g}$ & 0.23 & $23 \%$ \\
\hline$\chi$ & 0.001 & $\bar{m}$ & 0.1 & $2.7 \%$ \\
\hline
\end{tabular}

The value of the elasticity of demand facing our imperfectly competitive firms, $\theta$, comes from the econometric work of Rotemberg and Woodford (1998). The continuously compounding quarterly discount rate of $\ln (1.007)$ is slightly lower than that implied by other studies (such as Kollman (1998) or Rotemberg and Woodford op. cit., for example). The reason for this is that these studies assume infinitely lived consumers so that their implied continuously compounding rate of $\ln (1.00747)$ is equivalent to an annualised real interest rate of around 3\%. Since the existence of finite lives in our model raises the real rate of interest above consumers' rate of time preference, this slightly lower rate of time preference is consistent with the same equilibrium real interest rate.

The $k$ parameter is the probability of death for our consumers. This value implies that consumers have an expected working life of 30 years. Although this may be thought to imply an implausible value for the probability of death, it is necessary to generate a plausible steady-state value of government debt relative to GDP - the implied debt to GDP ratio of $70 \%$ is the same as for the Euro area in 2000 (ECB (2001)). This mark-up can be justified as reflecting uncertainty not formally captured in our model. For example, Faruqee et al (1997), show that taking the probability of death story literally implies near Ricardian consumption behaviour. They then show that extending the model to allow for non-monotonic life-time earnings profiles 
effectively raises the interest rate mark-up in the equation for aggregate human wealth in a manner consistent with our calibrated parameter.

$\tau$ is our basic rate of income tax and is set at $25 \%$. The $\kappa$ parameter is chosen to normalise the level of output to 1 to ease comparison of the steady-state levels of other variables. While the parameter $\alpha$ measures the instantaneous probability that a firm will be able to reset its price. Therefore, $\frac{1}{\alpha}$ measures the average length of time between price changes. A value of $\frac{1}{\alpha}=3.5$, means that it takes, on average, 10.5 months for firms to reset prices. This figure sits half way between the 3 quarter (see Rotemberg and Woodford (1997), for example) and 1 year (see Erceg et al (2001)) expected contract lengths commonly adopted in the literature. It is also consistent with econometric estimates of this parameter for the Euro area in Gali et al (2001) and Leith and Malley (2001).

We consider two values for $\mathrm{m}$, the coefficient on excess inflation in the Taylor rule. The first value of $\mathrm{m}$ of 0.5 is widely used in studies of interest rate reaction functions; see Taylor (1993) for example. We contrast this with a value of -0.5 - this implies a monetary policy which only adjusts nominal interest rates by half the rise in inflation such that real rates fall. Finally, we assume, that the parameter governing the importance of money in utility is 0.001 , implying that the stock of government liabilities issued in the form of cash or deposits is $2.7 \%$ of GDP, relative to overall government liabilities of $70 \%$ of GDP. Again these figures are consistent with the euro area at the end of 2000 (ECB (2001)). This parameterisation, therefore allows a small role for seigniorage revenues in the analysis that follows.

The steady-state these parameters imply are shown in the right-hand-side of the table. The real interest rate has an annualised value of around 3\%, and the steadystate ratio of debt to GDP is around 70\%, which is consistent with figures for the Euro area economies. The ratio of government spending to GDP of just under $25 \%$ is also typical of European economies if you eliminate transfers from the definition of government spending to be left with government consumption as defined in our model (see Gali (1994), for a comparison of this ratio across OECD economies).

We can now consider the implications of our stability analysis given the assumed parameters of our model. 


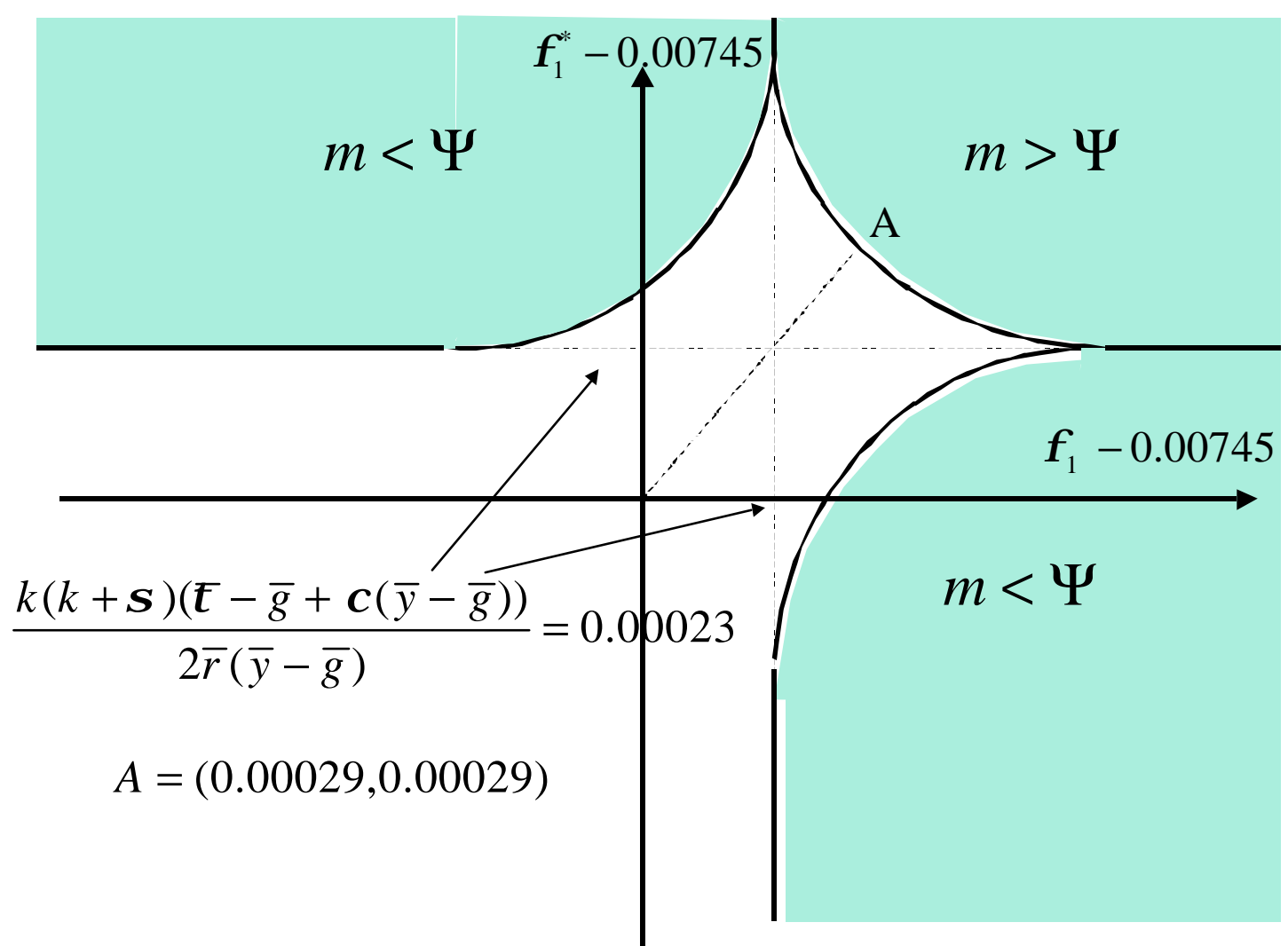

Figure 2 replicates Figure 1, but utilises the parameter values detailed in Table 1 to quantify the importance of the ability for one fiscal authority to compensate for the behaviour of another. Point A represents the two feedback parameters that are consistent with an 'active' monetary policy, and which minimise the average level of fiscal response across the union. The parameter values suggest that if both fiscal authorities ran policies such that $\phi_{1}>0.00774$ and $\phi_{1}{ }^{*}>0.00774$ (i.e. for every one Euro of debt disequilibrium taxes have to adjust by at least 0.00774 Euros) then the monetary authorities would be free to actively target inflation. If one fiscal authority failed to meet this level of fiscal feedback then the other may be able to compensate for their behaviour, although only in the range of $0.00768<\phi_{1}^{*}<0.00774$, such that the monetary authority could still run an 'active' monetary policy. In other words, although there is the theoretical possibility of one fiscal authority compensating for the lax fiscal behaviour of another, the range over which this is possible is very small, and could require a very large fiscal response on the part of the compensating authority. Since the minimum degree of fiscal feedback required of each authority is relatively low it seems far more likely that the only sustainable policy space is if both 
fiscal authorities act to fulfil this condition leaving the monetary authorities to target inflation.

\section{Simulations:}

In this section we analyse the paths of aggregate variables in our two economies in the face of shocks under various descriptions of policy. The shock we consider is a fiscal shock which raises the real value of debt by $10 \%$, cet. par $^{13}$. Figure 3 gives the paths for inflation, consumption and debt when monetary policy actively targets inflation, such that $m=0.5$, and the fiscal authorities act to stabilise debt in accordance with fiscal feedback parameters of $\phi_{1}=\phi_{1}^{*}=0.1$. In other words, given the steady-state implied by our assumed model parameters, they raise tax revenues by $1 \%$ for every $1 \%$ increase in their liabilities relative to their steady-state values. Since the economies and the shock hitting them is symmetrical, there is no distinction between the paths of variables in country 1 and 2 .

The main thing to note about these results is that even although consumers are non-Ricardian, and discount the future far more heavily that an infinitely lived consumer would, this still has a negligible impact on consumption and inflation due to the 'active' response of monetary policy. The initial impact on inflation is only $0.008 \%$ and consumption only rises by $0.005 \%$. In this simulation debt was assumed to be fully indexed. However, when debt is denominated in nominal terms the surprise inflation associated with the fiscal shock serves to reduce the initial increase in the real value of debt. However, the increase in inflation is so small that the effects are negligible.

We can then contrast these simulations with an example of our 'passive' regime. Specifically, we assume that the fiscal authority in country 2 refuses to adjust tax revenues in the face of debt disequilibrium i.e. $\phi_{1}^{*}=0$. The monetary authority is then forced to adopt a monetary policy that will ensure fiscal solvency in country 2 we assume $m=-0.5$. Finally, the fiscal authority in country 1 acts prudently with a fiscal feedback parameter of 0.1 . Figure 4 reveals the paths of inflation, consumption and government liabilities in both countries when government debt is fully indexed

\footnotetext{
${ }^{13}$ To the extent that the governments' liabilities are denominated in nominal terms, any surprise inflation as a result of the shock may result in the initial increase in debt being different from $10 \%$.
} 
and when it is nominal. In these cases the impact of the same fiscal shock on inflation and consumption is far more significant - inflation rises by almost $6 \%$ on impact and consumption by almost $10 \%$ when debt is fully indexed, and by almost $4 \%$ and $7 \%$, respectively when debt is nominal. The reason is that the ECB's 'passive' monetary policy does not raise real interest rates in response to excess inflation as this would lead to a debt interest spiral in country 2 . This loosening of monetary policy, boosts the discounted value of human wealth which increases consumption. Given the nominal inertia in the two economies this will feed through into both higher consumption and inflation. The paths for government debt in the two economies are slightly different - the active fiscal feedback in country 1 stabilises the debt stock more quickly, while using monetary policy to stabilise the debt stock in country two leads to liabilities actually falling below target after $1 \frac{1 / 2}{2}$ years. It should also be noted that the different fiscal policies also imply different paths for consumption and inflation in the two economies - consumers in country 1 suffer an increase in taxation which consumers in country 2 avoid. However, as was seen in figure 3 the impact on aggregate demand from debt even with this degree of non-Ricardian behaviour is negligible, and is difficult to discern from the graphs.

Figure 4, also contains the paths for variables when debt is denominated in nominal terms. Here, the initial increase in debt is almost halved as a result of the surprise inflation induced by the fiscal shock. This is essentially the mechanism underlying the Fiscal Theory of the Price Level - if prices were fully flexible then the fiscal shock could be completely eliminated by a one-off jump in the price level. However, in the presence of nominal inertia, not all prices are free to jump to eliminate the fiscal disequilibrium. As a result, the monetary authorities still need to act 'passively' to avoid an explosive path for debt in country 2, although the initial surprise inflation has made their job much easier. Therefore, real interest rates need not fall by as much, and the slacker monetary policy does not feed consumption and inflation to the same extent.

These results suggest that it is desirable to ensure that the monetary union is in the active monetary policy regime, but that modest fiscal feedback is sufficient to insure that debt disequilibrium does not have a significant impact on inflation. What would be the consequence of one economy stabilising debt much more rapidly, while adjustment in the other economy remained modest? If the modest response of one fiscal authority imposed significant costs on the other economy, then this may serve 
as a rationale for the Pact for Stability and Growth. To answer this question, the final simulations we consider are the case of the ECB engaged in the fight against inflation, $\mathrm{m}=0.5$, while the fiscal authority in country 1 targets its debt stock with the fiscal feedback parameter $\phi_{1}=0.1$, but country 2 employs an extremely aggressive fiscal policy, $\phi_{1}^{*}=9.4$, adjusting tax revenues by $100 \%$ for every $1 \%$ such that deviation of public liabilities from their steady-state value. Figure 5 details the paths of inflation, consumption, government liabilities and private sector financial wealth in the face of the same fiscal shock. Again the magnitude of the changes in consumption and inflation are very small for the reasons discussed above. The strong fiscal response in country 2 means that its debt stock is returned to steady-state very quickly. In country 1 the response is more gradual. This means that consumption in country 1 is given a greater boost due to the relative delay in fiscal correction there. As this increase in aggregate demand in country 1 feeds into demand for products in both economies prices rise in both economies. The ECB responds by raising real interest rates, which partially offsets the rise in consumption in country 1 and actually reduces consumption in country 2 . The initial price increase in country 1 is greater than in country 2 as workers in country one require greater wage increases to supply their labour as they now desire to substitute their higher consumption for leisure. The path for private sector financial assets reflects the path for government liabilities, although there is some difference in the medium run as terms of trade effects result in consumers in country 1 holding some of the debt of country 2 . Thus, although different speeds of debt correction lead to differences in response between countries, the overall impact on inflation is small. This model does not imply that the enforcement of rapid correction of debt disequilibrium is necessary to stabilise inflation in a monetary union.

\section{$\underline{\text { 4.Conclusions }}$}

In this paper we constructed a two country model which contained a number features which broke the distinction between Ricardian and non-Ricardian policies highlighted by the Fiscal Theory of the Price Level (Woodford, op. cit.). Specifically, our two economies featured overlapping generations of consumers who did not expect to live forever - as a result the government's liabilities (money and bonds) constitute 
an element of net wealth and their level will affect real interest rates in our economies. These consumers then supplied labour to imperfectly competitive firms who sold their output at home and abroad. These imperfectly competitive firms could only adjust their prices at random intervals. The combination of non-Ricardian consumers, and the nominal inertia facing imperfectly competitive firms implied that both monetary and fiscal policy could have real and nominal effects in both countries.

We then analysed the restrictions on policy necessary to ensure that our economies were saddlepath stable. In the context of the dynamic system analysed this implies that these restrictions would deliver a fully determined path for prices and would also prevent indefinite transfers of wealth from one economy to the other. Despite the complexity of the model we were able to derive a number of analytical results. First, the degree of fiscal response running from government debt to taxation required to ensure fiscal solvency is higher in the presence of non-Ricardian consumers. Second, we were able to identify two underlying policy regimes consistent with a fully determined path of prices and stable stocks of debt in both economies. In the first regime the monetary authorities implement a common monetary policy which raises nominal interest rates, such that real interest rates rise in response to excess inflation. This 'active' targeting of inflation requires the fiscal authorities to act to stabilise their liabilities. However, it was possible for one fiscal authority to compensate, to some extent, for a relatively weak fiscal response on the part of another monetary union member. In the second policy regime, one fiscal authority did not act to stabilise its liabilities, and the other fiscal authority was unable to compensate for this behaviour without transferring the wealth of its citizens abroad. In this regime, the only way to stabilise debt in both economies is for the monetary authority to abandon its 'active' targeting of inflation such that increases in inflation will reduce real interest rates and stabilise the debt in the country which runs an insolvent fiscal policy. The remaining fiscal authorities must then ensure that their fiscal policies are independently solvent. Finally, we calibrated the model and generated a plausible steady-state. We found, for plausible parameter values, that the scope for one fiscal authority to compensate for weak correction in the other was very limited. However, the degree of fiscal feedback required to ensure fiscal solvency was not very onerous. It also suggested that differences in the speed of fiscal correction, once this critical rate was reached, are not material in affecting the paths of macroeconomic variables in the face of shocks. However, when we moved to the 
regime where the monetary authorities are forced to abandon the active targeting of inflation, then the impact of fiscal shocks on inflation and output were now significant. It was also shown that having government debt denominated in nominal terms allowed surprise inflation to eliminate a significant part of any debt disequilibrium so that monetary policy had less to do in this respect. 


\section{References:}

Barro, R. J. (1979), "On the Determination of the Public Debt", Journal of Political Economy, Vol. 87, pp 940-71.

Bergin, P. R. (2000), "Fiscal Solvency and Price Level Determination in a Monetary Union", Journal of Monetary Economics, No. 45, pp37-53

Blinder, A. S. (1994), “On Sticky Prices: Academic Theories Meet the Real World”, In N.G. Mankiw ed, Monetary Policy, Pub. University of Chicago Press.

Calvo, G. (1983), "Staggered Prices in a Utility Maximising Framework", Journal of Monetary Economics, No. 12(3), pp 383-298

Canzoneri, M. B., R. E. Cumby and B. T. Diba (2001), "Fiscal Discipline and Exchange Rate Systems", Economic Journal, No. 474, PP 667-690.

Daniel, B. C. (2001), "The Fiscal Theory of the Price Level in an Open Economy", Journal of Monetary Economics, No. 48, pp293-308.

Dupor, B. (2000), "Exchange Rates and the Fiscal Theory of the Price Level”, Journal of Monetary Economics, No. 45, pp 613-630.

Erceg, C. J., D. W. Henderson and A. T. Levin (2000), 'Optimal Monetary Policy with Staggered Wage and Price Contracts', Journal of Monetary Economics 46, pp281-313.

ECB (2001), "Euro Area Statistics” Monthly Bulletin, August 2001, pp1*-83*.

Faruqee, H., D. Laxton and S. Symansky (1997), "Government Debt, Life-Cycle Income, and Liquidity Constraints: Beyond Approximate Ricardian Equivalence", IMF Staff Papers, Vol. 44, No.3, pp374-382. 
Gali, J. (1994), "Government Size and Macroeconomic Stability", European Economic Review, No. 28, pp117-132.

Gali, J., M. Gertler and G. D. Lopez-Salido (2001), "European Inflation Dynamics", European Economic Review, 45, pp 1237-1270.

Goodfriend, M. and R. King (1997), “The New Classical Synthesis and the Role of Monetary Policy", NBER Macroeconomics Annual, 1997, pp231-282.

Kashyap, A. K. (1995), "Sticky Prices: New Evidence from Retail Catalogues", quarterly Journal of Economics Vol. 110(1), pp245-274.

Kollman, R. "International Financial Markets and G7 Business Cycles: A General Equilibrium Approach with Money and Nominal Rigidities", University Paris XII mimeo.

Leeper, E. M. (1991), “Equilibria under 'Active' and 'Passive' Fiscal Policies". Journal of Monetary Economics, No. 27, pp 129-147.

Leith, C. and J. Malley (2001), "Estimated General Equilibrium Models for the Evaluation of Monetary Policy in the US and Europe", mimeograph, University of Glasgow

Leith, C. and S. Wren-Lewis (2000), "Interactions Between Monetary and Fiscal Policy Rules", Economic Journal, Vol. 110, No. 462, pp 93-108.

Leith, C. and S. Wren-Lewis (2001), "Interactions Between Monetary and Fiscal Policy in an Open Economy", University of Glasgow, mimeograph.

Obsfeldt, M. and K. Rogoff (1995), "Exchange Rate Dynamics Redux", Journal of Political Economy, No. 103, pp 624-660.

Rotemberg, J. J. and M. Woodford (1998), “An Optimization-Based Econometric Framework for the Evaluation of Monetary Policy: Expanded Version", NBER Technical Working Paper No. 233. 
Sargent, T. and N. Wallace (1981), "Some Unpleasant Monetarist Arithmetic", Federal Reserve Bank of Minneapolis Quarterly Review.

Sims, C. A. (1997), "Fiscal Foundations of Price Stability in Open Economies", Yale University, mimeograph.

Taylor, J. (1993), "Discretion Versus Policy Rules in Practice", Carnegie-Rochester Series on Public Policy, Vol 39, pp195-214.

Woodford, M. (1995), "Price-Level Determinacy Without Control of a Monetary Aggregate”, Carnegie-Rochester Conference Series on Public Policy, No. 43, pp1-53.

Woodford, M. (1996), "Control of the Public Debt: A Requirement for Price Stability?" NBER Working Paper No. 5684.

Woodford, M. (1998), "Control of the Public Debt: A Requirement for Price Stability?" in G. Calvo and M. King (eds) The Debt Burden and its Consequences for Monetary Policy, Pub. St Martin's Press, New York. 


\section{Appendix 1 - Log-Linearising the Model}

We now proceed to log-linearise the model around the symmetrical steady-state. To illustrate this consider the labour supply equation,

$$
N_{t}=\frac{w_{t}}{\kappa} \int_{-\infty}^{t} \frac{1}{c_{t}^{i}} k \exp (k(i-t)) d i
$$

Taking the natural logarithm of both sides, differentiating with respect to time and evaluating this expression at the symmetrical steady-state yields,

$$
\hat{N}_{t}=\widehat{w}_{t}-\int_{-\infty}^{t} \hat{c}_{t}^{i} k \exp (k(i-t)) d i=\hat{w}_{t}-\hat{c}_{t}
$$

Where a hatted variable denotes the percentage deviation from steady-state, $\hat{X}_{t}=\frac{\left.d X_{t}\right|_{x=\bar{x}}}{\bar{X}}$. This approach can be applied to all the equations in our model.

Next, consider the linearised expression for the optimal price set by a home firm,

$$
\tilde{\tilde{p}}_{t}=\int_{t}^{\infty}(\bar{r}+\alpha)\left[\widehat{P}_{s}+\widehat{w}_{s}\right] \exp (-(\bar{r}+\alpha)(s-t) d s
$$

Differentiating this expression with respect to time and substituting for the definition of consumer prices, $\hat{P}_{t}=\frac{1}{2} \hat{p}(h)_{t}+\frac{1}{2}\left(\hat{p}(f)_{t}\right)$, yields,

$$
d \widehat{\tilde{p}}_{t}=(\bar{r}+\alpha)\left(\tilde{\tilde{p}}_{t}-\frac{1}{2} \hat{p}(h)_{t}-\frac{1}{2} \hat{p}(f)_{t}-\widehat{w}_{s}\right)
$$

Log-linearising the expression for the index of home country output prices gives,

$$
\left.\hat{p}(h)_{t}=\int_{-\infty}^{t} \alpha \hat{\tilde{p}}_{s} \exp (-\alpha(t-s)) d s\right]
$$


Differentiating with respect to time,

$$
d \hat{p}(h)_{t}=\alpha\left(\hat{\tilde{p}}_{t}-\hat{p}(h)_{t}\right)
$$

Differentiating again,

$$
\begin{aligned}
d \hat{\pi}(h)_{t} & =\alpha\left(d \hat{\tilde{p}}_{t}-d \hat{p}(h)_{t}\right) \\
& =\bar{r} \hat{\pi}(h)_{t}-\alpha(\alpha+\bar{r}) \hat{w}_{t}+\alpha(\alpha+\bar{r})\left(\frac{1}{2} \hat{p}(h)_{t}-\frac{1}{2} \hat{p}(f)_{t}\right)
\end{aligned}
$$

Substituting the linearised labour supply function into this expression yields,

$$
d \hat{\pi}(h)_{t}=\bar{r} \hat{\pi}(h)_{t}-\alpha(\alpha+\bar{r})\left(\hat{c}_{t}+\hat{y}_{t}\right)+\alpha(\alpha+\bar{r})\left(\frac{1}{2} \hat{p}(h)_{t}-\frac{1}{2} \hat{p}(f)_{t}\right)
$$

This is the same as the usual New Keynesian Philips curve, except that there now exists a terms of trade-effect in addition to the usual output gap effect. A similar expression can be derived in terms of foreign output prices.

$$
d \hat{\pi}(f)_{t}=\bar{r} \hat{\pi}(f)_{t}-\alpha(\alpha+\bar{r})\left(\hat{c}_{t}^{*}+\hat{y}_{t}^{*}\right)+\alpha(\alpha+\bar{r})\left(\frac{1}{2} \hat{p}(f)_{t}-\frac{1}{2} \hat{p}(h)_{t}\right)
$$

We can then eliminate the terms of trade from the each country's Philips curve by noting the log-linearised definition of average home firm output,

$$
\hat{y}_{t}=-\theta \hat{p}(h)_{t}+\theta \hat{P}_{t}+\frac{1}{2}\left(\frac{1-\bar{g}}{\bar{y}}\left(\hat{c}_{t}+\hat{c}_{t}^{*}\right)+\frac{\bar{g}}{\bar{y}}\left(\hat{g}_{t}+\hat{g}_{t}^{*}\right)\right)
$$

and average foreign firm output,

$$
\hat{y}_{t}^{*}=-\theta \hat{p}(f)_{t}+\theta \hat{P}_{t}^{*}+\frac{1}{2}\left(\frac{1-\bar{g}}{\bar{y}}\left(\hat{c}_{t}+\hat{c}_{t}^{*}\right)+\frac{\bar{g}}{\bar{y}}\left(\hat{g}_{t}+\hat{g}_{t}^{*}\right)\right)
$$


Combining these expressions, using the definition the definition of PPP, and the global goods market clearing condition $\hat{y}_{t}+\hat{y}_{t}^{*}=\frac{1-\bar{g}}{\bar{y}}\left(\hat{c}_{t}+\hat{c}_{t}^{*}\right)+\frac{\bar{g}}{\bar{y}}\left(\hat{g}_{t}+\hat{g}_{t}^{*}\right)$, allows us to rewrite the home economy's Philips curve as,

$$
d \hat{\pi}(h)_{t}=\bar{r} \hat{\pi}(h)_{t}-\alpha(\alpha+\bar{r})\left(\hat{c}_{t}+\hat{y}_{t}\right)-\frac{\alpha(\alpha+\bar{r})}{\theta}\left(\frac{1}{2} \hat{y}_{t}-\frac{1}{2} \hat{y}_{t}^{*}\right)
$$

While the corresponding equation for the foreign economy is given by,

$$
d \hat{\pi}(f)_{t}=\bar{r} \hat{\pi}(f)_{t}-\alpha(\alpha+\bar{r})\left(\hat{c}_{t}^{*}+\hat{y}_{t}^{*}\right)-\frac{\alpha(\alpha+\bar{r})}{\theta}\left(\frac{1}{2} \hat{y}_{t}^{*}-\frac{1}{2} \hat{y}_{t}\right)
$$

Now consider the domestic government's budget constraint in terms of real total government liabilities ${ }^{14}$,

$$
d l_{t}=r_{t} l_{t}-\left(r_{t}+\pi_{t}\right) m_{t}+g_{t}-\tau_{t}
$$

where $l_{t}=\frac{D_{t}+F_{t}^{*}+M_{t}}{P_{t}}$. Log-linearising yields,

$$
d \hat{l}_{t}=\hat{r}_{t-1}+\left(\bar{r}-\frac{\bar{m}}{\bar{l}} \bar{r}\right) \hat{r}_{t}-\bar{r} \frac{\bar{m}}{\bar{l}} \hat{m}_{t}-\frac{\bar{m}}{\bar{l}} \hat{\pi}_{t}+\frac{\bar{g}}{\bar{l}} \hat{g}_{t}-\frac{\bar{\tau}}{\bar{l}} \hat{\tau}_{t}
$$

Substituting for steady-state values of variables by noting that $\frac{\bar{m}}{\bar{l}}=\frac{\chi \bar{c}}{\bar{\tau}-\bar{g}+\chi \bar{c}}$ and $\frac{\tau}{\bar{l}}=\frac{\bar{\tau} \bar{r}}{\bar{\tau}-\bar{g}+\chi \bar{c}}$, and assuming that $\hat{g}_{t}=0, \forall t$ yields,

$$
d \hat{l}_{t}=\hat{r}_{t-1}+\left(\bar{r}-\frac{\chi \bar{c}}{\bar{\tau}-\bar{g}+\chi \bar{c}} \bar{r}\right) \hat{r}_{t}-\frac{\chi \bar{c}}{\bar{\tau}-\bar{g}+\chi \bar{c}} \hat{\pi}_{t}-\frac{\chi \overline{c r}}{\bar{\tau}-\bar{g}+\chi \bar{c}} \hat{m}_{t}-\frac{\bar{\tau} \bar{r}}{\bar{\tau}-\bar{g}+\chi \bar{c}}\left(\hat{\tau}_{t}\right)
$$

\footnotetext{
${ }^{14}$ Since we are interesting in describing the evolution of the economy after the shock has hit, we can ignore the distinction between ex ante and ex post real rates in log-linearising the government's flow budget constraint. It should be noted that this distinction will, however, be fully accounted for in the simulations presented in section 3 .
} 
If we assume, for simplicity, that the monetary authority distributes any seigniorage revenues equally between both fiscal authorities then we can rewrite this as,

$$
d \hat{l}_{t}=\hat{r}_{t}+\bar{r} \hat{r}_{t}-\frac{\chi \overline{c r}}{\bar{\tau}-\bar{g}+\chi \bar{c}}\left(\frac{1}{2} \hat{c}_{t}+\frac{1}{2} \hat{c}_{t}^{*}\right)-\frac{\bar{\tau} \bar{r}}{\bar{\tau}-\bar{g}+\chi \bar{c}} \hat{\tau}_{t}
$$

Similarly for the foreign government we have,

$$
d \hat{l}_{t}^{*}=\hat{r}_{t}^{*}+\bar{r} \hat{r}_{t}-\frac{\chi \overline{c r}}{\bar{\tau}-\bar{g}+\chi \bar{c}}\left(\frac{1}{2} \hat{c}_{t}+\frac{1}{2} \hat{c}_{t}^{*}\right)-\frac{\bar{\tau} \bar{r}}{\bar{\tau}-\bar{g}+\chi \bar{c}} \epsilon_{t}^{*}
$$

In our open economy the evolution of private sector financial assets in the home country is given by,

$$
d a_{t}=r_{t} a_{t}-(1+\chi) c_{t}+y_{t}-\tau_{t}
$$

Log-linearising yields,

$$
d \hat{a}_{t}=\overline{r a}_{t}+\overline{r r}_{t}-(1+\chi) \frac{\overline{r c}}{\bar{\tau}-\bar{g}+\chi \bar{c}} \hat{c}_{t}+\frac{\overline{r y}}{\bar{\tau}-\bar{g}+\chi \bar{c}} \hat{y}_{t}-\frac{\bar{\tau} r}{\bar{\tau}-\bar{g}+\chi \bar{c}} \hat{\tau}_{t}
$$

Again there is a corresponding equation for the foreign economy,

$$
d \hat{a}_{t}=\bar{r} \hat{a}_{t}^{*}+\bar{r} \hat{r}_{t}-(1+\chi) \frac{\overline{r c}}{\bar{\tau}-\bar{g}+\chi \bar{c}} \hat{c}_{t}^{*}+\frac{\overline{r y}}{\bar{\tau}-\bar{g}+\chi \bar{c}} \hat{y}_{t}^{*}-\frac{\bar{\tau} \bar{r}}{\bar{\tau}-\bar{g}+\chi \bar{c}} \hat{\tau}_{t}^{*}
$$

Any increase in the level of the financial wealth of the private sector relative to the liabilities of the government implies an increase in holdings of foreign government debt.

Now we turn to the consumption function,

$$
c_{t}=(k+\sigma)\left(\frac{A_{t}}{P_{t}}+\int_{t}^{\infty}\left(y_{s}-\tau_{s}\right) \exp \left(-\int_{t}^{s}(r(\mu)+k) d \mu\right) d s\right.
$$

Differentiating with respect to time, 


$$
d c_{t}=(k+\sigma)\left(d a_{t}+d h_{t}\right)
$$

where, human wealth is given by $h_{t}=\int_{t}^{\infty}\left(y_{s}-\tau_{s}\right) \exp \left(-\int_{t}^{s}(r(\mu)+k) d \mu\right) d s$, and $d h_{t}=\left(r_{t}+k\right) h_{t}-y_{t}+\tau_{t}$. Using the equations of motion for human and non-human wealth allows us to requite the equation of motion for consumption as,

$$
d c_{t}=\left(r_{t}+k-(k+\sigma)(1+\chi)\right) c_{t}-k(k+\sigma) a_{t}
$$

In log-linearised form for the home country,

$$
d \hat{c}_{t}=(\bar{r}+k-(k+\sigma)(1+\chi)) \hat{c}_{t}+\overline{r r} \hat{r}_{t}-k(k+\sigma) \frac{\bar{\tau}-\bar{g}+\chi \bar{c}}{\overline{r c}} \hat{a}_{t}
$$

and for the foreign country,

$$
d \hat{c}_{t}^{*}=(\bar{r}+k-(k+\sigma)(1+\chi)) \hat{c}_{t}^{*}+\overline{r r}_{t}-k(k+\sigma) \frac{\bar{\tau}-\bar{g}+\chi \bar{c}}{\overline{r c}} \hat{a}_{t}^{*}
$$

This is the usual consumption Euler equation, adjusted for holdings of money balances and allowing for the possibility that finites lives mean that government debt constitutes and element in net wealth.

Finally, we need to consider the determination of output (since this is not synonymous with consumption in our open economy). Consider the definition of home firm output,

$$
\hat{y}_{t}=-\theta \hat{p}(h)_{t}+\theta \hat{P}_{t}^{*}+\frac{1}{2}\left(\frac{1-\bar{g}}{\bar{y}}\left(\hat{c}_{t}+\hat{c}_{t}^{*}\right)+\frac{\bar{g}}{\bar{y}}\left(\hat{g}_{t}+\hat{g}_{t}^{*}\right)\right)
$$

Noting that the definition of consumer prices implies that $\hat{P}_{t}=\frac{1}{2} \hat{p}(h)_{t}+\frac{1}{2}\left(\hat{p}(f)_{t}\right)$ it can be seen that home firm output depends upon aggregate demand and the real 
exchange rate, which can be defined as, $\hat{e}_{t}=\hat{p}(h)_{t}-\hat{p}(f)_{t}$. Therefore, any terms in output can be replaced with a combination of the real exchange rate and the components of aggregate demand, $\hat{c}_{t}, \hat{c}_{t}^{*}, \hat{g}_{t}$ and $\hat{g}_{t}^{*}$. To do so we need to add an equation describing the evolution of the real exchange rate,

$$
d \hat{e}_{t}=\hat{\pi}(h)_{t}-\hat{\pi}(f)_{t}
$$

which is a predetermined variable in our system due to the overlapping price contracts in our model. We can then use equation (78) to eliminate output from the other equations of the system. 
Appendix 2 - Simulation Results ${ }^{15}$

Figure 3: 'Active' Monetary Policy

Figure 4 'Passive' Monetary Policy with and Symmetrical Solvent Fiscal Policy

Nominal and Real Debt.

Inflation
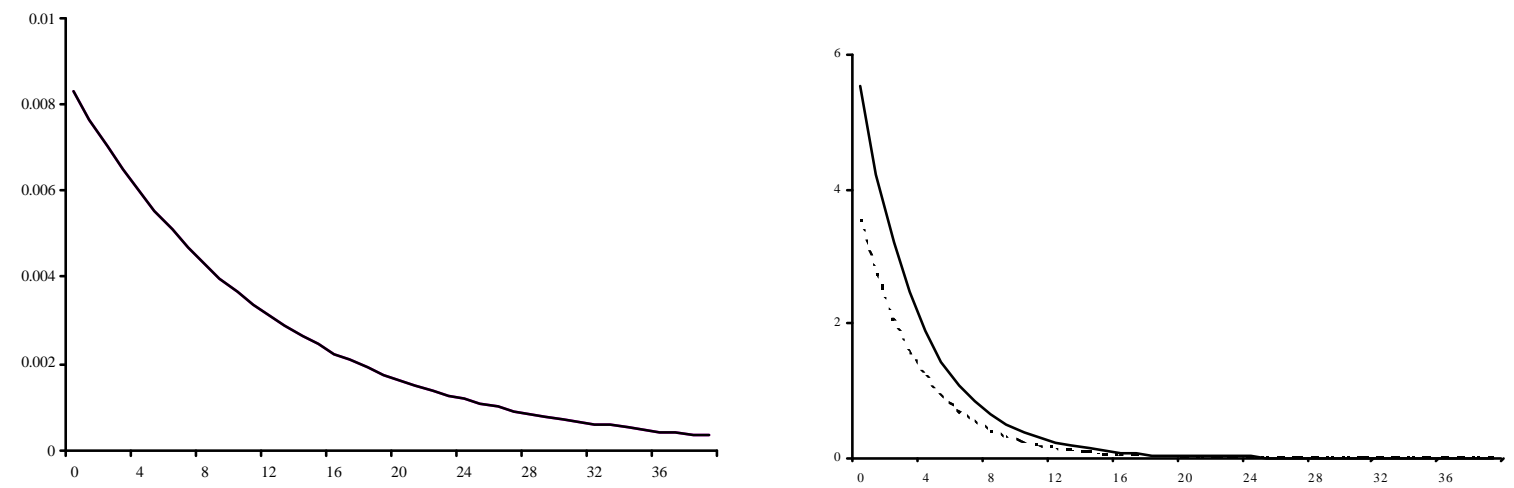

\section{Consumption}

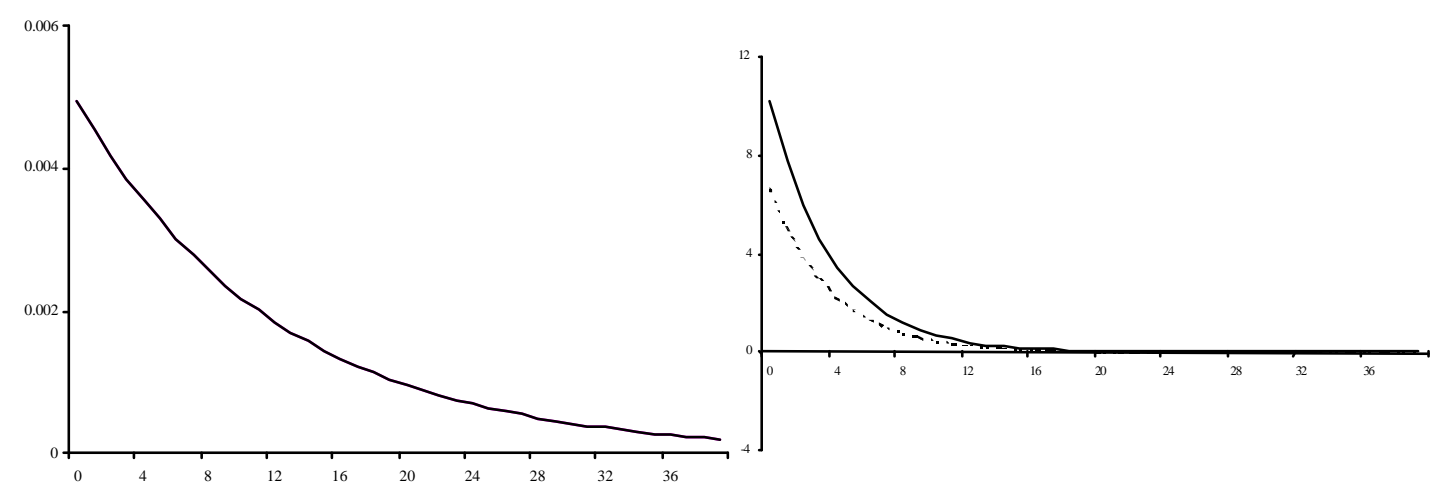

Government Liabilities
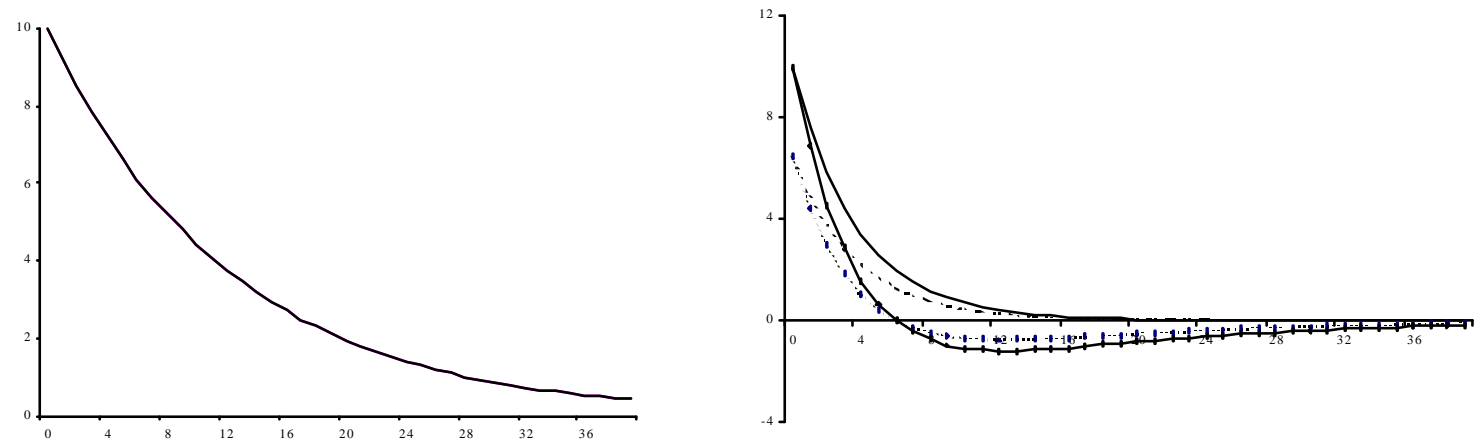

\footnotetext{
${ }^{15}$ Inflation is measured as a percentage, and all other variables are measured as a percentage deviations from steady-state. Dotted lines refer to solution values when debt is nominal, and solid lines refer to simulations where debt is fully indexed. In the final chart, diamonds denote country two. In all other charts solution values are indistinguishable between country 1 and 2 .
} 
Figure 5: 'Active' Monetary Policy and Asymmetric Solvent Fiscal Policy

\section{Inflation}

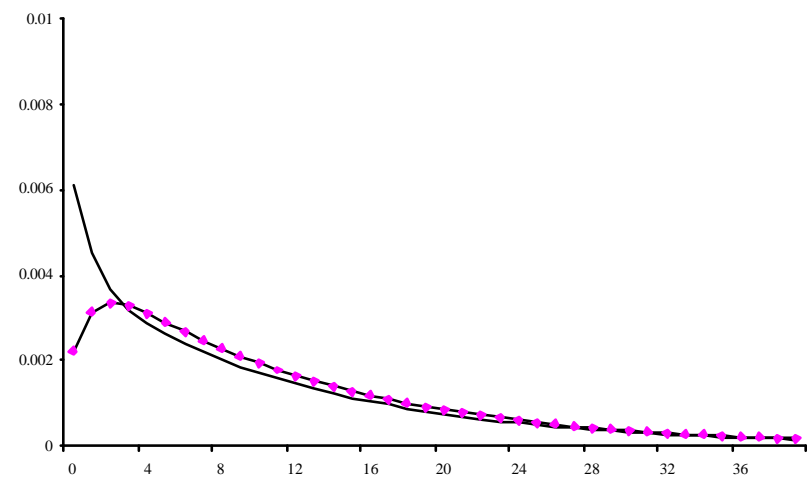

Consumption

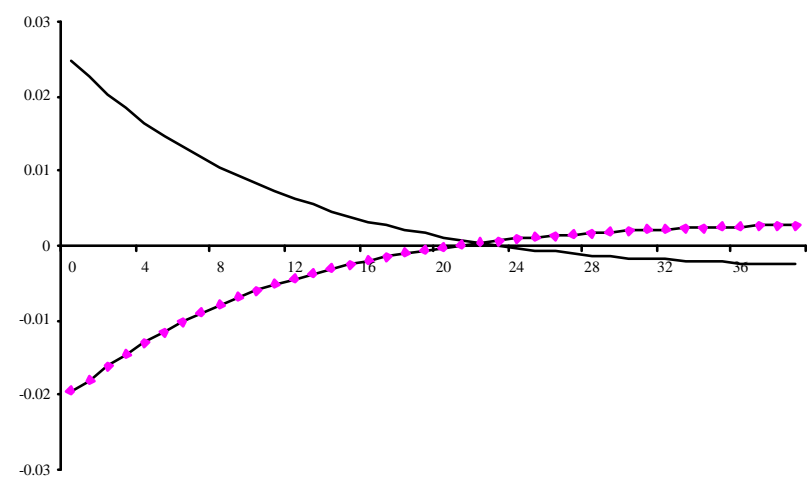

Government Liabilities

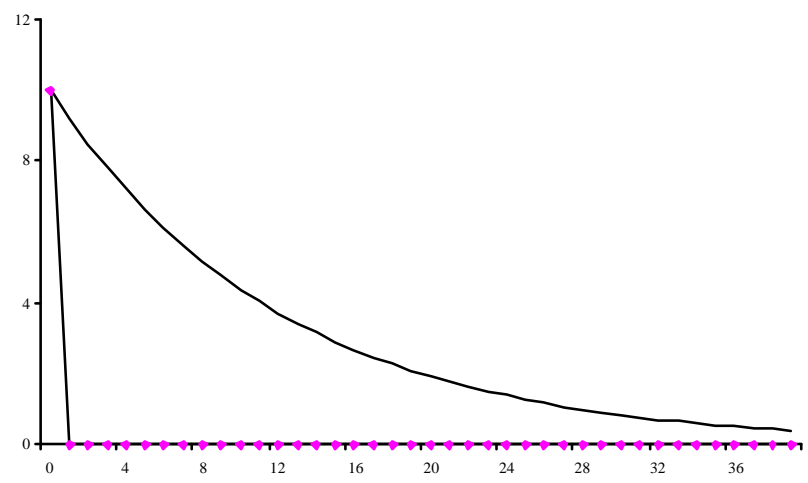

Financial Assets

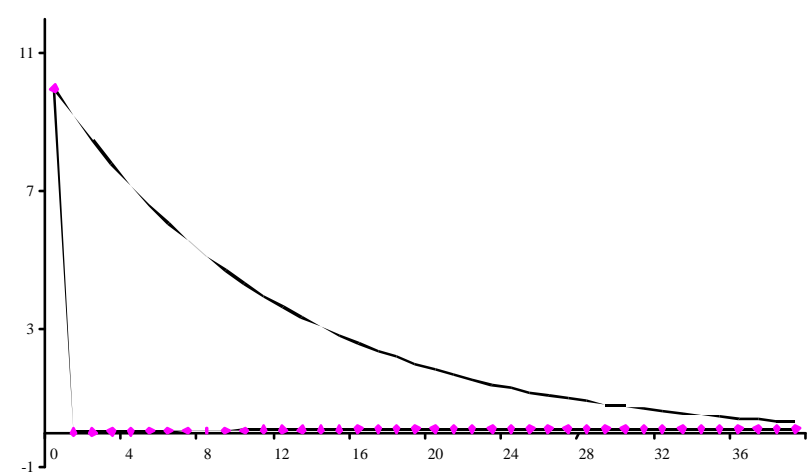

